\title{
PERENCANAAN PENINGKATAN KUALITAS DENGAN MENGGUNAKAN INTEGRASI METODE SIX SIGMA DAN ISO 9001:2000
}

\author{
IMRON KUSWANDI \\ Jurusan Teknik Industri Universitas Trunojoyo \\ Jl Raya Telang PO BOX 2 Kamal, Bangkalan 69162 \\ Telepon (031) 3011147, Fax (031) 3011506
}

\begin{abstract}
Companies who produce several of cigarettes, one of the kinds is BM Universal 12. To produce product with best quality and due to give satisfaction toward its consumer, there are several problem faced by the cigarette production process which is there are still defect product in its production process. From this condition, they need one method to deal with the matter. Using six sigma methods, they can identify defect product and by doing that they could improve the quality of the product. In this experiment it's using integration method by combining six sigma method and ISO 9001:2000. Six sigma methods is expected to be able minimizing the defect in PT "X" by creating production process more effectively, better performance of the company and still fulfilling the need and the satisfaction of the consumer while also making efforts to improve and inclined its quality. Meanwhile ISO 9001:2000, is an international standard that has orientation toward the qualifying products. Based on its internal data and observation commence inside the company, there would be only three main clauses from ISO 9001:2000 requirements that is going to be made as measuring points of product quality improvement, which is clause 5 (management responsibilities), 7 (product realization) and 8 (measurement, analysis and improvement). While Six Sigma phase comprises of Define, Measure, Analyze and Improve. In Define phase there would be defining the product, the making of Six Sigma team and the making of production flow process. Measure has 3 kind defects that usually have bigger percentage than other defects which is unbalance weight defect (including empty shell) and korep defect. The percentage that goes with unbalance weight defect (including empty shell) is 41.9\% and korep defect with $21.03 \%$ from all three defect we gained DPMO value reaching 7776 and sigma level reaching 3,9. By viewing the FMEA and RPN, the improvement alternatives that suppose to be done by the company is creating job instruction, implementing job instruction in rolling process then the company should be able to save Rp3,942,975.00 for one month.
\end{abstract}

Key words: six sigma, DPMO, FMEA, ISO 9001:2000, quality

\section{PENDAHULUAN}

Kualitas merupakan salah satu jaminan yang diberikan dan harus dipenuhi oleh perusahaan kepada pelanggan termasuk pada kualitas produk. Karena kualitas suatu produk merupakan salah satu kriteria penting yang menjadi pertimbangan pelanggan dalam memilih produk. Selain di mata pelanggan, kualitas juga merupakan salah satu indikator penting bagi perusahaan untuk dapat eksis di tengah ketatnya persaingan dalam dunia industri. Oleh karena itu, diperlukan perbaikan dan peningkatan kualitas secara terus-menerus dari perusahaan sesuai dengan spesifikasi dan kebutuhan pelanggan. Untuk mencapai tujuan perusahaan yang ingin memperoleh profit serta memuaskan pelanggan, maka perusahaan perlu untuk menerapkan ISO 9001:2000, karena hal ini akan meningkatkan produktivitas, efisiensi, efektivitas operasional dan mengurangi biaya yang ditimbulkan barang cacat (defect) atau barang bermutu rendah dan limbah.

Kondisi di atas berlaku juga pada PT "X" yang merupakan salah satu perusahaan yang menghasilkan berbagai macam jenis rokok salah satunya BM Universal 12. Misi perusahaan ini adalah untuk memproduksi barang dengan kualitas terbaik dan memberikan kepuasan kepada pelanggan, akan tetapi terdapat beberapa hambatan yang masih dihadapi oleh PT "X" tersebut dalam proses produksi rokok, yaitu 
masih terdapat produk cacat (defect) dalam proses produksinya. Upaya untuk meningkatkan kualitas dapat dilakukan dengan penerapan metode six sigma. Dengan metode six sigma, ditujukan agar dapat mengidentifikasi defect serta meningkatkan kualitas produk. Dalam penelitian ini digunakan suatu integrasi, yaitu antara metode six sigma dan ISO 9001:2000. Metode Six Sigma yang diharapkan dapat meminimasi terjadinya defect di PT "X" dengan menciptakan suatu kinerja proses produksi yang lebih efektif, lebih ramping dengan performansi yang lebih baik serta tetap memenuhi kebutuhan dan kepuasan konsumen. dan berusaha untuk melakukan perbaikan dan peningkatan kualitas. Sedangkan ISO 9001:2000, merupakan suatu standar internasional yang berorientasi pada produk yang berkualitas.

Namun, jika Six Sigma dan ISO 9001: 2000 berdiri sendiri-sendiri, maka akan muncul kelemahan. Jika six sigma berdiri sendiri, maka proses ini hanya akan fokus pada satu masalah atau isu saja, serta sistem dokumentasi dari setiap tahapan tidak diatur. Sedangkanjika ISO 9001:2000 berdiri sendiri, maka ISO akan membahas mengenai hal yang global, di antaranya hal yang menyangkut sistem manajemen mutu saja, kurang berorientasi pada proses produksi maupun perbaikkan kualitas. Maka Integrasi antara six sigma dan ISO 9001:2000, mempunyai keunggulan, yaitu tidak akan hanya fokus pada satu isue saja melainkan keseluruhan proses dan sistem manajemen mutu perusahaan, dan juga proses peningkatan kualitas dapat didokumentasikan guna mengevaluasi serta mengaudit hasil dari peningkatan kualitas.

Berdasarkan hal tersebut, maka penelitian ini dilakukan untuk memperbaiki kualitas rokok agar dapat mengurangi jumlah defect yang ada dengan menggunakan siklus DMAI (Define, Analize, Measure, Improve) pada six sigma. Serta menintegrasikan rancangan kerja perbaikan kualitas dengan ISO 9001:2000, guna mendapatkan kepercayaan dari konsumen. Tujuan penelitian adalah merencanakan peningkatan kualitas dengan menggunakan integrasi metode six sigma dan ISO 9001:2000.

\section{METODE}

Seluruh data dan informasi dikumpulkan dan kemudian diolah sesuai dengan metode yang telah ditetapkan. Tahap ini merupakan penerapan siklus DMAIC pada Six Sigma, yang meliputi Define dan Measure, serta integrasinya dengan berdasarkan kalusul ISO 9001:2000. Setiap langkah dalam tahapan define, measure, analyze, akan diintegrasikan dengan ISO 9001:2000. Tiaptiap langkah akan disesuaikan dengan klausul mana yang mempunyai bahasan mengenai langkahlangkah tersebut.

Define. Tahap ini merupakan tahap awal dari siklus DMAIC pada Six Sigma di mana pada tahap awal langkah-langkah yang dilakukan adalah sebagai berikut. Menentukan produk yang menjadi objek penelitian. Pembentukan tim Six Sigma. Pembentukan tim Six Sigma yang melibatkan orang-orang yang mengerti akan proses produksi rokok. Penggambaran seluruh proses produksi.

Measure.Tahapinimerupakantahapkelanjutan dari tahap define dimana pada tahap ini akan dilakukan pemilihan karakteristik CTQ dengan menggunakan diagram pareto, mengidentifikasi standar performansi, pengumpulan data yang dibutuhkan yang nantinya akan dilakukan perhitungan nilai sigma dengan menggunakan pembacaan tabel atau SPC Wizard's Calculator sigma yang nantinya akan dijadikan sebagai baseline performance.

Analyze. Analyze merupakan tahap ketiga dalam siklus DMAIC. Pada tahap ini dilakukan integrasi antara tahapan Analyze dengan klausul yang mempunyai kesesuaian dengan langkahlangkah pada tahap analyze, dan pada tahap analyze dilakukan analisis kapabilitas proses dan pengidentifikasian penyebab terjadinya defect dengan menggunakan Cause dan Effect diagram. Diagram ini dibuat dengan jalan pengamatan di lapangan dan diskusi diantara tim Six Sigma. Serta menggunakan FMEA untuk mengidentifikasi potensi kegagalan yang ditimbulkan pada proses produksi sehingga perlu diperbaiki dengan melihat nilai RPN tertinggi. 
Improve. Setelah akar permasalahan diketahui, maka langkah selanjutnya adalah melakukan perencanaan tindakan perbaikan untuk mengatasi atau mencegah defect dengan melihat RPN tertinggi pada FMEA, serta penyesuaian dengan klausul yang mempunyai kesesuaian dengan langkahlangkah pada tahap improve. Rencana tindakan yang didapat dari nilai RPN tertinggi bertujuan untuk mengembangkan dan mengimplementasikan perbaikan untuk menurunkan DPMO dan meningkatkan level sigma-nya sehingga pada tahap Analyze diharapkan mampu mengurangi defect yang ada pada perusahaan.

\section{HASIL DAN PEMBAHASAN}

Berdasarkan data internal dan pengamatan yang dilakukan di perusahaan, maka hanya 3 klausul utama dari persyaratan ISO 9001:2000 yang akan digunakan sebagai tolak ukur perbaikan kualitas produk, yaitu klausul 5 (tanggung jawab manajemen), 7 (realisasi produk), dan klausul 8 (Pengukuran, analisa dan perbaikan).

Tabel 1. Tabel Integrasi antara Tahapan-tahapan Six Sigma dengan Klausul-klausul ISO-9001:2000.

\begin{tabular}{|c|c|c|c|c|}
\hline \multirow{2}{*}{$\begin{array}{l}\text { Tahapan } \\
\text { Six Sigma }\end{array}$} & \multirow{2}{*}{ Action } & \multicolumn{2}{|r|}{ Integrasi ISO } & \multirow{2}{*}{ Kesesuaian } \\
\hline & & Klausul & Isi & \\
\hline \multirow[t]{3}{*}{ Define } & $\begin{array}{l}\text { - Menentukan produk } \\
\text { sebagai bahan } \\
\text { penelitian }\end{array}$ & - 7.5 .3 & $\begin{array}{l}\text { - Identifikasi dan } \\
\text { kemampuan telusuran }\end{array}$ & $\begin{array}{l}\text { Perusahaan harus mampu untuk } \\
\text { menidentifikasi maupun menelusuri } \\
\text { produk mana yang menjadi produk } \\
\text { paling diminati, dengan begitu maka } \\
\text { perusahaan diharapklan untuk lebih } \\
\text { menekan jumlah defect pada produk } \\
\text { tersebut karena produk tersebut paling } \\
\text { diminati }\end{array}$ \\
\hline & $\begin{array}{l}\text { - Pembentukan Team Six } \\
\text { Sigma }\end{array}$ & - 5.5 .1 & $\begin{array}{l}\text { - Tanggung Jawab dan } \\
\text { wewenang }\end{array}$ & $\begin{array}{l}\text { Manajemen harus memastikan bahwa } \\
\text { tanggung jawab dan wewenang } \\
\text { didefinisikan dan dikomunikasikan } \\
\text { didalam team, serta membuat } \\
\text { penugasan-penugasan ke dalam program } \\
\text { six sigma untuk memberikan kualitas } \\
\text { produk dan mencapai target six sigma }\end{array}$ \\
\hline & $\begin{array}{l}\text { - Penggambaran Proses } \\
\text { Produksi }\end{array}$ & - 7.6 & $\begin{array}{l}\text { - Pengendalian alat dan } \\
\text { pemantauan }\end{array}$ & $\begin{array}{l}\text { Penggambaran proses produksi } \\
\text { bertujuan untuk memantau maupun } \\
\text { memberikan bukti bahwa produk } \\
\text { telah sesuai dengan persyaratan yang } \\
\text { ditentukan. }\end{array}$ \\
\hline \multirow[t]{3}{*}{ Measure } & $\begin{array}{l}\text { - Identifikasi cacat utama } \\
\text { dengan diagram pareto }\end{array}$ & - 8.2 .4 & $\begin{array}{l}\text { - Pemantauan dan } \\
\text { pengukuran produk }\end{array}$ & $\begin{array}{l}\text { Perusahaan menentukkan defect mana } \\
\text { yang menjadi perhatian utama guna } \\
\text { memenuhi persyaratan yang diinginkan } \\
\text { oleh pelanggan, serta perusahaan } \\
\text { mengukur sejauh mana cacat pada } \\
\text { produk tersebut terhadap hasil produksi } \\
\text { di perusahaan. }\end{array}$ \\
\hline & & - 8.3 & $\begin{array}{l}\text { - Pengendalian Produk } \\
\text { yang tidak sesuai }\end{array}$ & $\begin{array}{l}\text { Perusahaan harus memastikkan bahwa } \\
\text { produk yang tidak sesuai terhadap } \\
\text { persyaratan yang diinginkan pelanggan, } \\
\text { serta perusahaan mendefinisikan defect } \\
\text { yang menjadi permasalahan keluhan } \\
\text { para pelanggan. }\end{array}$ \\
\hline & - Mengidentifikasi CTQ & - 8.2 .1 & - Kepuasan Pelanggan & $\begin{array}{l}\text { Perusahaan harus mampu } \\
\text { mengidentifikasi CTQ terbesar guna } \\
\text { mengetahui karateristik produk yang } \\
\text { memengaruhi kepuasan pelanggan. }\end{array}$ \\
\hline
\end{tabular}




\section{Lanjutan Tabel 1}

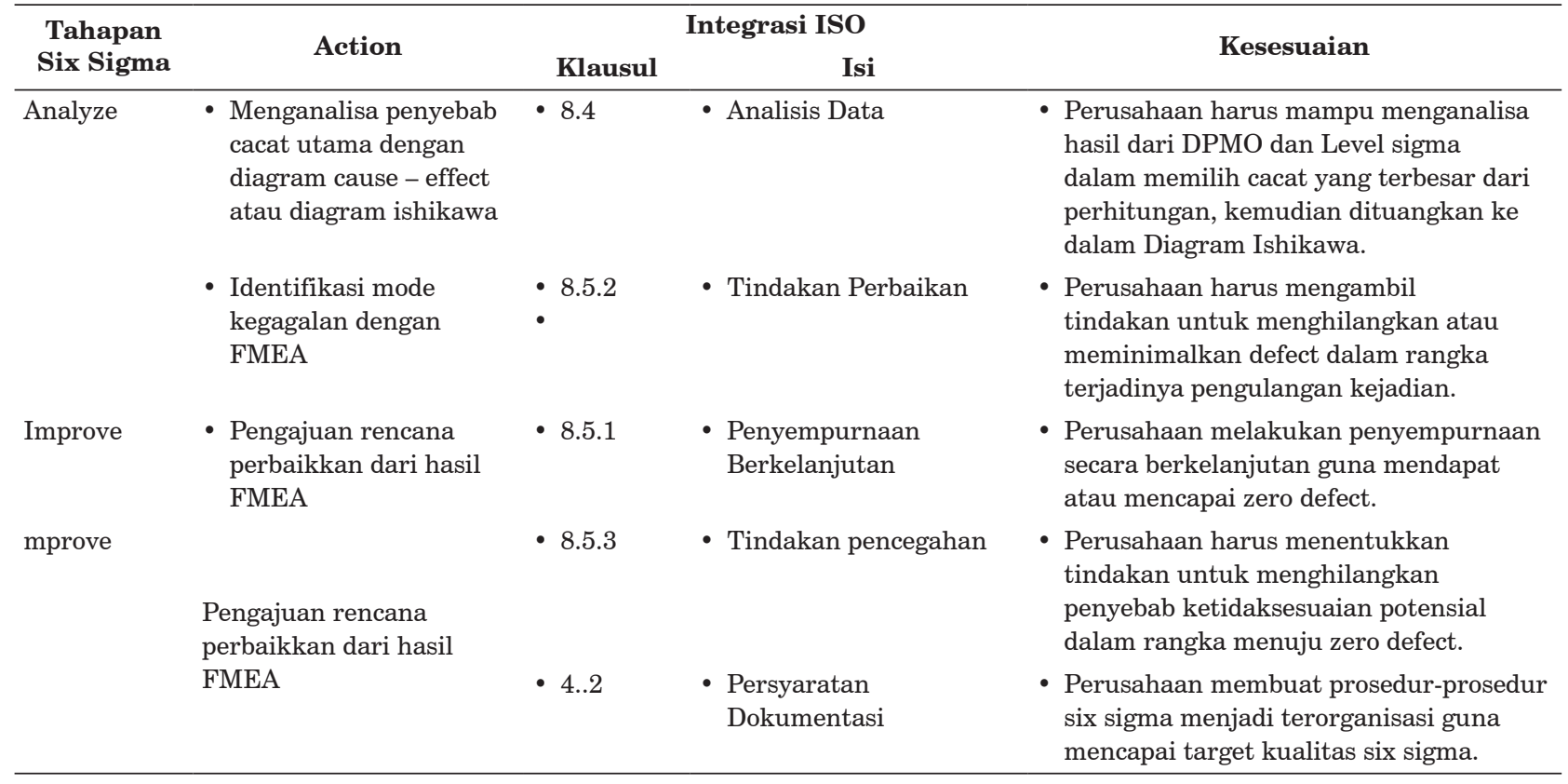

Melihat penyesuaian klausul ISO ke Six Sigma di atas maka perusahaan disarankan untuk memiliki komitmen kuat untuk meningkatkan kualitas dan atau sedang mengapdosi sistem manajemen kualitas ISO 9001:2000, sebaiknya mempertimbangkan untuk mengintegrasikan atau menjadikan program six sigma sebagai model peningkatan kualitas. Jika perusahaan memungkinkan untuk melakukan penyesuaian peningkatan kualitas dan ISO 9001:2000, maka perusahaan dapat mengambil langkah-langkah dari penyesuaian integrasi antara six sigma dan ISO 9001:2000: Klausul 4. Sistem Manajemen Kualitas. Klausul 4.2 Persyaratan Dokumen. Manajemen menulis praktek-prektek terbaik dalam program six sigma ke dalam prosedur-prosedur standar yang relevan. Klausul 4.2.3. Pengendalian Dokumen. Membuat prosedur-prosedur six sigma itu menjadi tergorganisasi untuk mencapai target kualitas six sigma. Klausul 5. Tanggung Jawab Manajemen. Klausul 5.5.1 Tanggung Jawab, Wewenang, dan Komunikasi. Merumuskan atau membuat penugasan-penugasan atau pengalokasian sumbersumber daya ke dalam program six sigma untuk memberikan kualitas produk. Menjamin agar setiap orang yang berada di team memperoleh informasi yang relevan tentang program six sigma. Klausul 7. Realisasi Produk. Klausul 7.6 Pengendalian
Peralatan Pengukuran dan Pemantauan. Menggunakan peralatan itu dengan tepat guna atau sesuai, dan melakukan pemantauan maupun perawatan mesin secara periodik. Klausul 8. Pengukuran, Analisis dan Peningkatan. Klausul 8.2 Pengukuran dan Pemantauan. Memelihara kepuasan total pelanggan menuju target kualitas six sigma. Klausul 8.4 Analisis Data. Mengumpulkan data, melakukan analisa data dan memetakan serta menginterpretasikan tentang hal-hal yang berarti terkait dengan informasi itu dari setiap proyek six sigma.

Identifikasi Produk yang Dijadikan Obyek Penelitian (Klausul 7.5.3). Pada langkah yang pertama ini, yaitu menetukkan produk yang akan dijadikan obyek penelitian mempunyai kesesuaian dengan klausul 7.5.3 yaitu tentang identifikasi dan kemampuan telusuran, dimana perusahaan harus mempunyai kemampuan mengidentifikasi maupun telusur terhadap produk yang menjadi produk terlaris maupun produk yang sering menjadi complain customer hal ini perlu dilakukan karena perusahaan harus menjaga dan memelihara kepercayaan para konsumen. Pada penelitian ini hanya difokuskan pada salah satu jenis rokok yang dapat dilihat dari besarnya total produksi yang dihasilkan selama tiga bulan mulai bulan Oktober, November dan Desember. Kemudian dari hasil 
pemilihan jenis rokok tersebut akan dilakukan pemilihan salah satu produk yang dihasilkan dari jenis rokok itu sendiri dapat dilihat dari perbedaan persentase cacat yang tertinggi yang nantinya akan dilakukan perbaikan pada proyek six sigma. Hal ini dikarenakan produk rokok sangat meluas dan bersaing di dunia pemasaran. Sehingga pemilihan fokus perlu dilakukan untuk meningkatkan daya saing produk dan menurunkan terjadinya cacat.

Pemilihan produk amatan menjadikan keterkaitannya dengan kepuasan customer yang diwujudkan dalam kesediaan mereka untuk tetap bersedia membeli produk sesuai dengan spesifikasi dan keinginan mereka. Kemudian juga berdasarkan identifikasi yang dilakukan, potensi defect atau cacat pada rokok ini terbilang cukup banyak dimana pada pembahasan lebih lanjut defect-defect ini nantinya akan menjadi CTQ (Critical to Quality) dari produk rokok itu sendiri.

Berikut ini akan ditunjukkan hasil dari data besarnya jumlah produksi jenis rokok selama periode bulan Oktober, November dan Desember 2007 pada PT. Bokormas lihat Tabel 2.

Berdasarkan tabel di atas menunjukkan perbandingan antara jumlah produksi rokok yang diproduksi selama bulan oktober sampai desember dimana jika dilihat secara grafis total produksi yang dihasilkan Bokormas Universal Limited Edition pada bulan tersebut jumlahnya sangat kecil bila dibandingkan dengan total jumlah produksi jenis BM Super 12 yaitu 3.384 .000 dan jenis BM Universal 12 ternyata menjadi banyak pilihan bagi para perokok dengan jumlah produksi selama bulan Oktober sampai desember sebanyak 88.748.880. Maka yang menjadi fokus amatan dari ketiga jenis rokok yaitu pada jenis BM Universal 12, karena proses produksi yang dihasilkan dalam 3 periode terakhir bulan Oktober sampai Desember yang paling tinggi produksinya. Karena semakin tinggi tingkat penjualan maka produksi rokok yang dihasilkan akan semakin banyak dan kemungkinan akan berakibat semakin banyaknya cacat produk yang ada, selain itu pemilihan produk BM universal ini didasarkan pada data jumlah produk cacat yang terjadi yaitu BM universal 12 sebanyak 6,4\%, BM super 12 sebesar 2,5\% dan BM limited 12 sebesar $4,73 \%$. Jenis produk amatan rokok ini sangat meluas dan bersaing di dunia pemasaran. Sehingga pemilihan fokus amatan ini perlu dilakukan untuk meningkatkan daya saing produk dan menurunkan terjadinya cacat.

Pemilihan produk amatan menjadikan keterkaitannya dengan kepuasan customer yang diwujudkan dalam kesediaan mereka untuk tetap mau membeli produk sesuai dengan spesifikasi dan keinginan mereka. Kemudian juga berdasarkan identifikasi yang dilakukan, potensi defect atau cacat pada rokok ini terbilang cukup banyak dimana pada pembahasan lebih lanjut defect-defect ini nantinya akan menjadi CTQ (Critical to Quality) dari produk rokok itu sendiri. Pada langkah pembentukkan team six sigma ini, mempunyai kesesuaian dengan klausul 5.5.1 yaitu tentang Tanggung Jawab, Wewenang dan komunikasi, dimana manajemen harus memastikan bahwa tanggung jawab dan wewenang didefinisikan dan dikomunikasikan didalam team.

\section{MEASURE}

Measure merupakan langkah kedua dalam siklus DMAIC. Pada tahap ini dilakukan identifikasi terhadap jenis-jenis cacat yang kritis terhadap kualitas produk rokok, setelah itu dilakukan perhitungan DPMO serta level sigma dari sistem produksi rokok.

Penelitian ini dilakukan pada proses produksi di PT "X", pada setiap stasiun kerja atau pada masing-masing proses produksi yang mempunyai peluang mengalami kegagalan sehingga dapat menyebabkan cacat.

Dalam mengindetifikasi cacat departemen QC (Quality Control) yang bertugas memeriksa produk,

Tabel 2. Tabel Jumlah Produksi pada Bulan Oktober-Desember 2007

\begin{tabular}{|c|c|c|c|c|}
\hline \multirow{2}{*}{ Jenis Rokok } & \multicolumn{3}{|c|}{ Produksi (Batang) } & \multirow{2}{*}{ Jumlah } \\
\hline & Oktober & November & Desember & \\
\hline BM Universal 12 & 14.656 .800 & 38.401 .440 & 35.690 .640 & 88.748 .880 \\
\hline BM Super 12 & 3.972 .960 & 7.620 .120 & 5.517 .360 & 17.110 .440 \\
\hline BM Universal Limited Edition 12 & 669.600 & 1.512 .000 & 1.202 .400 & 3.384 .000 \\
\hline
\end{tabular}


apakah produk itu cacat atau layak/baik untuk dipasarkan. Adapun cacat pada produk rokok, jika kondisi fisiknya digolongkan sebagai berikut.

Korep/kertas ambri kotor (C1): Yaitu jenis cacat adanya bercak-bercak pada kertas ambri, hal ini terjadi saat proses penggilingan, batang rokok terlihat kotor karena adanya bercak-bercak tersebut.

Komposisi isi kurang sesuai/berat tidak stabil (C2): Cacat yang menyebabkan berat rokok tidak sesuai standar perusahaan, untuk standar dari perusahaan sendiri yaitu berat rokok $\pm 1,36-1,38$ gram.

Isi tembakau yang tidak rapi (C3): Dimana isi rokok tidak rapi, tembakau ada yang keluar dan ujungnya jadi tidak rapi.

Kopong/kurang pengisian tembakau (C4): Cacat ini bias dikatakan juga dalam kategori cacat berat tidak stabil, namun pada cacat ini biasanya batang rokok tidak diisi secara penuh oleh pekerja.

Kurang kolot/lem yang kurang (C5): Batang rokok kurang merekat, karena kurangnya pemerian lem ataupun tidak meratanya pemberian lem.

Pada tahapan identifikasi CTQ, perusahaan harus mampu untuk mengetahui jenis cacat yang timbul agar perusahaan dapat mengetahui informasi yang berhubungan dengan persepsi pelanggan terhadap defect produk. Untuk mengetahui CTQ maka harus diketahui frekuensi cacat pada tiap proses untuk mencegah produk cacat masuk ke proses berikutnya. Hasil inspeksi dari jenis-jenis cacat yang teridentifikasi di atas dibuat diagram Pareto untuk mengetahui jenis cacat yang paling sering muncul, sedangkan datadata yang akan diolah kedalam Pareto adalah data-data cacat selama 20 hari pengamatan lihat Tabel 3.
Diagram Pareto Rokok BM Universal 12

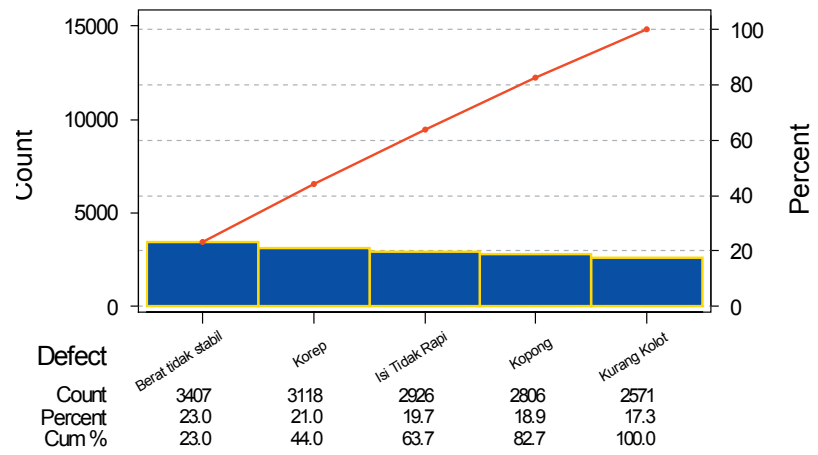

Gambar 1. Diagram pareto rokok BM Universal 12

Dari diagram Pareto di atas jenis-jenis cacat untuk kelima jenis cacat produk di atas tersebut diambil 2 cacat pada rokok berdasar prosentasenya, yaitu berat yang tidak stabil sebesar 22,98\% akan digabungakan dengan cacat kopong (18,92\%) karena cacat berat tidak stabil merupakan terlalu banyak pengisian maupun terlalu sedikit, sedangkan kopong sendiri merupakan cacat yang bagian tertentu pada batang rokok terlihat kopong (hal ini bisa dikatakan batang rokok kurang isi) dan Cacat Korep atau ada bercak pada kertas ambri sebesar $(21,03 \%)$.

Dengan demikian diketahui terdapat dua jenis cacat yang menjadi masalah utama (Critical to Quality) dalam kualitas produk rokok BM Universal 12, yaitu:

Berat Tidak Stabil/Kopong. Pada cacat berat tidak stabil ini atau kopong, sering disebabkan karena pekerja penggiling tidak atau kurang teliti dalam waktu melinting rokok dan mengisi rokok tersebut tidak memperhatikan isi tembakau atau komposisi bahan yang tidak sesuai standart.

Tabel 3. Tabel Data jumlah Total Cacat yang Terjadi Selama Bulan September 2008 Rokok BM Universal 12 PT Bokormas

\begin{tabular}{lcccc}
\hline \multicolumn{1}{c}{ Jenis Cacat } & Jumlah & Jumlah Kumulatif & Prosentase (\%) & Prosentase Kumulatif (\%) \\
\hline Korep & 3118 & 3118 & 21,03 & 21,03 \\
Berat tidak stabil & 3407 & 6525 & 22,98 & 44,01 \\
Isi Tidak Rapi & 2926 & 9451 & 19,73 & 63,74 \\
Kopong & 2806 & 12257 & 18,92 & 82,66 \\
Kurang Kolot & 2571 & 14828 & 17,34 & 100 \\
\hline \multicolumn{2}{l}{} \\
\hline
\end{tabular}


Korep/Muncul bercak-bercak pada kertas ambri. Batang rokok yang terdapat noda pada kertas ambri, disebabkan karena tangan pekerja penggiling yang masih terdapat lem bekas dari lem litingan sebelumnya, dan tergesa-gesa melakukan proses liting sehingga kertas ambri terkena lem dibagian luarnya yang menyebabkan tembakau yang ada didalamnya nampak seperti noda atau bercak-bercak di bagian kertas ambri tersebut yang terkena lem.

\section{Nilai DPMO dan Level Sigma}

Perusahaan harus mampu menganalisis data dari perhitungan DPMO dan Level Sigma, tujuanya untuk mengetahui berapa jumlah defect dalam per satu juta produksi, serta mampu mengevaluasi bila penyempurnaan berkelanjutan dapat dilaksanakan atau dilakukan.

Perhitungan nilai DPMO dan level sigma proses produksi BM Universal 12 dilakukan pada proses produksi stasiun kerja pelintingan, karena cacat pada proses ini selalu teridentifikasi atau selalu muncul. DPMO dihitung dengan rumus di bawah ini:

$$
\mathrm{DPMO}=\frac{\text { Jumlah unit cacat }}{\text { jumlah unit inspeksi } \mathrm{X} \text { jumlah CTQ }} \times 1.000 .000
$$

Memperkirakan Kapabilitas Proses

Berdasarkan nilai DPMO di atas proses produksi rokok saat ini mempunyai nilai level sigma sebesar 3,9 dan DPMO sebesar 7776 yang artinya bahwa dari 1.000.000 kemungkinan terjadinya kesalahan (defect) maka hanya terjadi 7776 kesalahan atau terdapat sekitar 3110 batang rokok cacat dalam proses produksi sebanyak 400000 rokok $(7776 / 1.000 .000 \times 400000=3110)$. Ditinjau dari level sigma maka kemampuan proses produksi rokok sudah berada di rata-rata perusahaan industri Indonesia. Upaya peningkatan kualitas produk rokok harus mampu menaikkan level sigma dari 3,9 setidaknya menjadi 4,0 dan menurunkan nilai DPMO.

\section{SIMPULAN}

Jenis cacat berat tidak stabil (termasuk kopong) dan korep. Dengan persentase untuk berat tidak stabil (termasuk kopong) sebesar 41,9\% dan cacat korep sebesar $21,03 \%$ penyebab terjadinya ketiga jenis cacat tersebut adalah sebagai berikut.

Berat tidak stabil (termasuk kopong) disebabkan karena kurangnya ketelitian dalam mengisi maupun melinting rokok, perusahaan mempunyai standar berat rokok sebesar 1,75 g, biasanya pekerja terlalu banyak maupun sedikit dalam mengisi rokok sehingga dapat menyebabkan isi batang rokok tidak rata.

Terdapat korep disebabkan karena pekerja yang ceroboh dan tergesa-gesa memberi lem pada kertas ambri, padahal perusahaan mempunyai standar bahwa pemberian lem dilakukan dengan max 250 kertas ambri, tapi para pekerja ceroboh dengan memberi lem lebih dari 250 kertas ambri secara bersamaan.

Tabel 4. Tabel Memperkirakan Kapabilitas Proses

\begin{tabular}{|c|c|c|c|}
\hline Langkah & Tindakan & Persamaan & Hasil Perhitungan \\
\hline 1 & Proses apa yang anda ingin mengetahui? & - & Pembuatan Rokok \\
\hline 2 & Berapa banyak unit produk yang diperiksa? & - & 400000 \\
\hline 3 & Berapa banyak unit produk yang cacat? & & 9331 \\
\hline 4 & Hitung tingkat cacat berdasarkan langkah $3 ?$ & $=$ Langkah 3/Langkah 2 & 0,0233275 \\
\hline 5 & $\begin{array}{l}\text { Tentukan banyaknya CTQ potensial yang dapat } \\
\text { mengakibatkan cacat? }\end{array}$ & $\begin{array}{c}=\text { Banyaknya karakteristik } \\
\text { CTQ }\end{array}$ & 3 \\
\hline 6 & Hitung pelung tingkat cacat per karakteristik CTQ? & $=$ Langkah 4/Langkah 5 & 0,077758 \\
\hline 7 & $\begin{array}{l}\text { Hitung kemungkinan cacat per satu juta kesempatan } \\
(\mathrm{DPMO}) ?\end{array}$ & $=$ Langkah $6 * 1000000$ & 7776 \\
\hline 8 & $\begin{array}{l}\text { Konversi DPMO (langkah 7) kedalam nilai sigma } \\
\text { (lihat table lampiran 5)? }\end{array}$ & & 3,9 \\
\hline 9 & Buat kesimpulan? & & $\begin{array}{l}\text { Kapabilitas Sigma } \\
\text { adalah } 3,9\end{array}$ \\
\hline
\end{tabular}


Guna untuk merencanakan peningkatan kualitas maka dilakukan pembuatan instruksi kerja pada proses pelintingan, dari hasil penerapan usulan perbaikkan didapat peningkatan level sigma dari 3,9 menjadi 4,1 serta penurunan DPMO dari 8100 menjadi 5333, hal ini diikuti dengan perusahaan dapat menghemat Rp3.942.975 per bulan.

\section{DAFTAR PUSTAKA}

Afrianto, Wahyu, 2005. Perancangan Sistem Manajemen Kualitas Berdasarkan ISO 9001:2000 di PT "X" di Surakarta, Surabaya: Jurusan Teknik Industri, Universitas Petra Surabaya.

Brue, Greg, 2005. Six Sigma for Managers (24 Acuan Untuk Memahami dan Menerapkan Prinsip-prinsip Six Sigma di Perusahaan). Jakarta: PT Media Global Edukasi.

Chatab, Nevizond, 1996. Panduan Penerapan Dan Sertifikasi Sistem Manajemen Mutu ISO 9000, Jakarta: PT Elex Media Komputindo.

Gaspersz, Vincent, 2002. Pedoman Implementasi Program Six Sigma Terintegrasi Dengan ISO 9001:2000, MBNQA, dan HACCP. Jakarta: PT Gramedia Pustaka Utama.

Ishikawa, Kaoru, 1988. Teknik Penuntun Pengendalian Mutu, Jakarta: Mediyatama Sarana Perkasa.
Lindsay, Evans, 2005. An Introduction to Six Sigma \& Process Improvement Pengantar Six Sigma, Jakarta: Salemba Empat.

Montgomery, Douglas, 1996. Pengantar Pengendalian Kualitas Statistik. Yogyakarta: Gajah Mada University Press.

Pande, Peter S, Neuman Robert P, and Roland R.Cavanagh, 2002. The Six Sigma Way: Bagaimana GE, Motorola, dan Perusahaan Terkenal Lainnya Mengasah Kinerja Mereka. McGraw-Hill.

Rothery, Brian, 1993. Analisis ISO 9000, Jakarta PT Pustaka Binaman Pressindo.

Suardi, Rudi, 2003. Sistem Manejemen Mutu ISO 9000:2000, Jakarta: CV Teruna Grafica.

(http://thevaluequest.wordpress.com/2007/05/31/sixsigma/)

(http://www.ebizzasia.com/0106-2003/columns,0106,04. $\underline{\mathrm{htm})}$

(http://qualityengineering.wordpress.com/tag/konsepsix-sigma/)

(http://www.iso.ch/iso/isn/en/howstd-dev.html)

(klik.uph.edu/iso/whatISO.php - 8k -)

(Qims.com/Consulting/Quality Services/ISO 9001:2000)

(http://dewey.petra.ac.id/dgt_res_detail. php?knokat $=6883$ )

(smksbivedcmalang.id.or.id/wp-content/uploads/2007/10/ perencanaan-penerapan-smm-iso-9001-2000.doc)

(dosen.amikom.ac.id/downloads/artikel/ STANDART\%20MUTU.doc)

(http://id.wikipedia.org/wiki/Rokok) 